\title{
Investigating the effects of knowledge management and organizational innovation on organizational strategy: Evidence from insurance industry
}

\author{
Seyed Mohsen Taheri ${ }^{a^{*}}$, Amir Homayoun Sarfaraz ${ }^{b}$ and Seyed Mohsen Seyed AliAkbar
}

${ }^{a}$ Master student, Department of Industrial Engineering, Islamic Azad University, South Tehran Branch, Tehran, Iran ${ }^{b}$ Associate Professor Department of Industrial Engineering, Islamic Azad University, South Tehran Branch, Tehran, Iran

\section{H R O N I C L E}

Article history:

Received June 4, 2014

Accepted 12 October 2014

Available online

October 172014

Knowledge Management

Innovation

Exploratory factor analysis

Insurance

Strategy \begin{abstract}
A B S T R A C T
This paper presents an exploratory factor analysis on knowledge management and organizational innovation items influencing on organizational strategy. The study designs a questionnaire in Likert scale and distributes it among 210 employees in an insurance firm named Dana located in Iran. Cronbach alpha has been well above 0.90, which confirms the validity of the overall survey. Using principle component analysis, the study extracts six critical success factors influencing on knowledge management including knowledge management processes, organizational culture, organizational structure, human resources, information technology, top management support and three factors of innovation including product innovation, process innovation, and organizational performance.
\end{abstract}

\section{Introduction}

In the age of communication and information technology, knowledge is known as the primary key and a critical source of organizations, to achieve sustainable competitive advantages. Therefore, by turning the industry-based economy into a knowledge-based economy, organizations also have to depend on their knowledge and apply it within the business process to increase their competitiveness. To understand on why some organizations are successful in the competition, it is necessary to understand the role of knowledge. Critical Success Factors (CSFs) are known as the primary sources for firm success and performance in several activity domains (Sedighi \& Zand, 2012). Knowledge management $(\mathrm{KM})$ is a managerial philosophy, which is perceivable in the practices of various firms. Utilizing knowledge management yields better performance by interaction between individuals or groups. However, KM is not an ultimate tool, which resolves all necessary information and knowledge creation problem. Moreover, to be efficient, knowledge management needs storage for information and knowledge to help organizations' members search for critical information, knowledge or the best practices. Thus, KM is a learning method for knowledge sharing (KS) and 
interaction and it clarifies which way to operate. KM needs to be considered an organizational process used to reach better performance because of effective KS and organizational learning, recognizing and developing competencies, and gaining from individuals' different skills and knowledge (Bairi et al., 2013). KM builds a new working environment where knowledge and experience can be shared, enables information and knowledge to emerge, and flows to the right people at the right time so they could act more efficiently and effectively (Akhavan et al., 2006).

Information technologies (IT) offers essential support for integration and building necessary knowledge. Many believe that IT could enhance both organizational processes and knowledge systems. It may also create numerous opportunities to transform products, processes and firms. On the other hand, IT supports the knowledge flows among the important actors and artifacts, and then enhances the new knowledge creation (Xiang-yang, 2007). Human resources management (HRM) builds a link between human capital management and KM within organizations (Jha, 2011). People are important because any changes or entry of new technology may infuence on the labors inside the organization; so it is necessary to evaluate the organizational culture and individual readiness for adoption of innovative and new technology (Asl et al., 2012).

Hierarchies play an important role in coordinating organizational activities and resources. Exploitative innovations depend on existing knowledge and they are driven by narrowing and converging processes of learning, which occur in periodic, stable conditions. Thus, mechanistic forms of most firms are efficient. On the contrary, exploratory innovations help creation of new knowledge. They are directed by the learning processes of expansion and divergence and $\mathrm{T}$ organic organization forms are preferred, next. Mechanistic forms of firm, characterized by hierarchical control, provide a relatively high level of control over tasks. On the contrary, organic forms of firms, characterized by dispersed control, shift task and innovation to the most knowledgeable parties (Xiang-yang, 2007)

Both of socio-cultural view and practice perspective of knowledge assume that learning contains a complex social process and new knowledge often is socially constructed and embedded within routine working practices (Xiang-yang, 2007). Many organizations apply various tools and methods to gain and to manage knowledge about customer's business processes and domain skills. The best approach used is a mix of technology solutions and human knowledge acquisition (Bairi et al., 2013). Table 1 represents a brief review of most important previous studies regarding innovation and knowledge management.

\section{Table 1}

The summary of recent studies on KM and innovation

\begin{tabular}{ll}
\hline Area & Reference \\
\hline $\begin{array}{l}\text { Knowledge management processes (knowledge creation, } \\
\text { knowledge using, knowledge acquisition, knowledge } \\
\text { sharing, knowledge and maintenance of knowledge) }\end{array}$ & $\begin{array}{l}\text { Xu et al., 2010; Huang \& Lai, 2012; Girard \& McIntyre, 2010; Alavi \& Leidner (2001); } \\
\text { Liao \& Wu, 2010 }\end{array}$ \\
$\begin{array}{l}\text { organizational culture } \\
\text { organizational structure } \\
\text { human resource management }\end{array}$ & $\begin{array}{l}\text { Girard \& McIntyre, 2010; Alavi \& Leidner, 2001; Liao \& Wu, 2010 } \\
\text { Lee \& Choi, 2003 }\end{array}$ \\
$\begin{array}{ll}\text { Huang, \& Lai, 2012; Lin, 2007; Girard \& McIntyre, 2010; Alavi \& Leidner, 2001; Liao \& } \\
\text { Wu, 2010 }\end{array}$ \\
$\begin{array}{ll}\text { Huang, \& Lai, 2012; Lin, 2007; Girard \& McIntyre, 2010; Alavi \& Leidner, 2001; Liao \& } \\
\text { Wu, 2010 }\end{array}$ \\
$\begin{array}{l}\text { López-Nicolás \& Meroño-Cerdán (2011); López-Nicolás \& Meroño-Cerdán, 2011; } \\
\text { Jiménez-Jiménez \& Sanz-Valle, 2011; Škerlavaj et al., 2010; Hung et al., 2011 }\end{array}$ \\
$\begin{array}{l}\text { López-Nicolás \& Meroño-Cerdán, 2011; López-Nicolás \& Meroño-Cerdán, 2011; Škerlavaj } \\
\text { et al., 2010; Hung et al., 2011 }\end{array}$ \\
$\begin{array}{l}\text { López-Nicolás \& Meroño-Cerdán, 2011; López-Nicolás \& Meroño-Cerdán, 2011; Škerlavaj } \\
\text { et al., 2010; Hung et al., 2011; Chen et al., 2010 }\end{array}$ \\
\hline
\end{tabular}


In this paper, we try to put the most appropriate knowledge management processes with respect to the comments of KM experts in the organization. According to Benbya et al. (2004), KM processes used are 1-Acquisition, 2-Create, 3-Use, 4-Distribute, 5-Store and 6-Hold. The proposed model in Fig. 1.

\section{The proposed study}

The purposed study defines the effect of innovation and knowledge management in strategy formulation examined by an insurance company. For this purpose, a study has been conducted to clarify the main elements of each factor. This study is presented as follows:

1- The related variables of innovation and KM are defined from previous papers.

2- These factors are investigated in a Delphi method and the finalized list is prepared.

3- A questionnaire is prepared to scale the factors.

4- An exploratory factor analysis is made to obtain the suggested model of the effects.

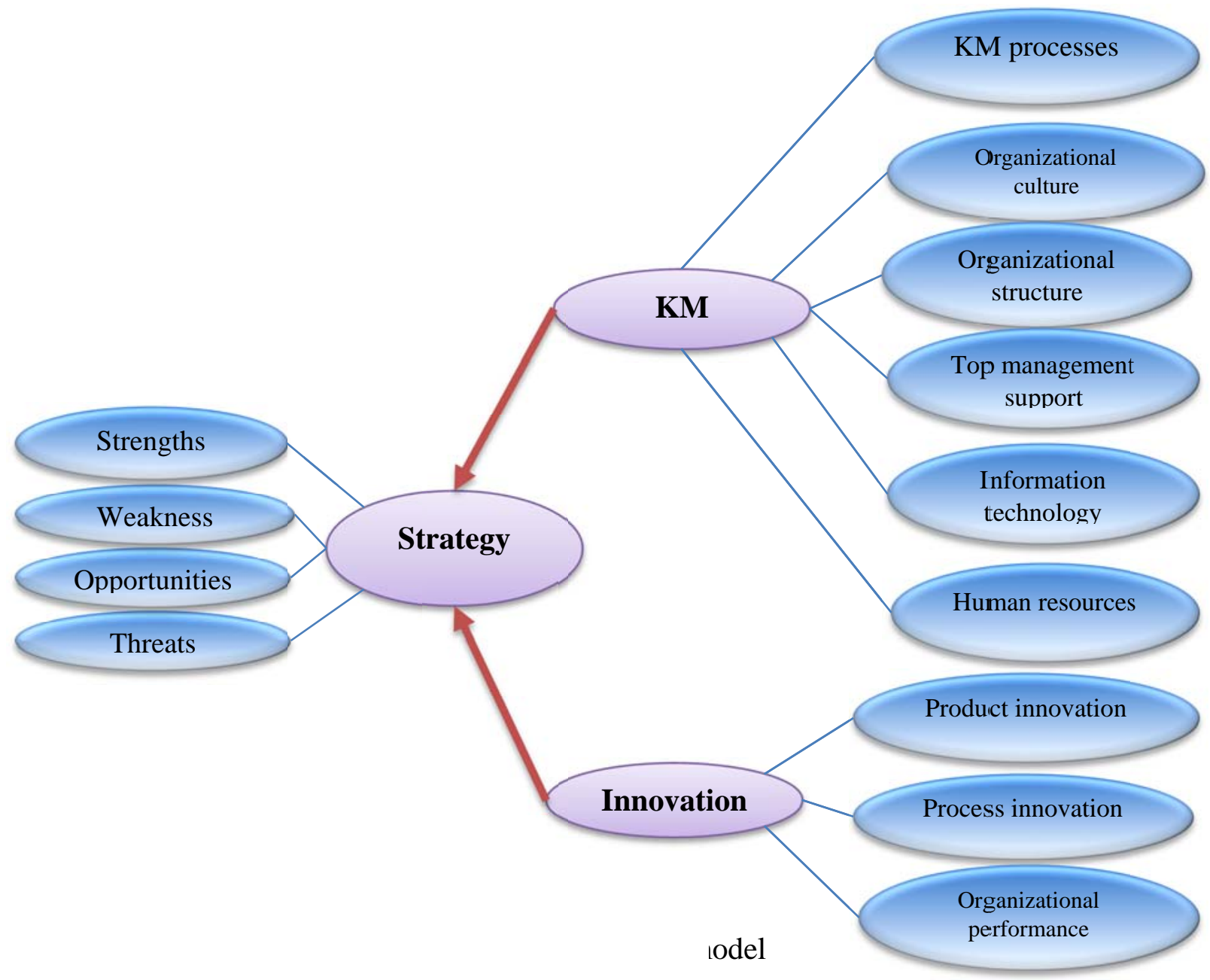

To evaluate and measure the concepts of $\mathrm{KM}$ and innovation, 9 factors and 54 questions are considered as initial variables from reviewing literature while 10 experts cooperated in Delphi method. The questionnaires were distributed and gathered randomly among 3:05 employees of Dana insurance company in Iran. Finally, 210 questionnaires were completed and were useable. Regarding the sensitivity of factor analysis to the absence of symmetry, some questions were omitted from the questionnaire. Every item was allocated five values from one to five representing very little, little, medium, much and very much. Cronbach alpha is used to verify the reliability of the questionnaire and it yielded 0.969, which is well above the minimum desirable level of 0.70 . According to Cronbach's Alpha result, it shows that questions involve multi-collinearity, so the questions that their 
Variance Inflation Factor (VIF) was greater than 2.75 have been deleted. Thus, the number of questions was dropped to 25 and Cronbach's alpha was reduced to about 90\%, which reveals good reliability of the questionnaire. KMO and Bartlett's test of sphericity produces the Kaiser-MeyerOlkin measure of sampling adequacy and Bartlett's test. The value of KMO should be greater than 0.5 if the sample is adequate.

Table 2

The summary of KMO test

Kaiser-Meyer-Olkin Measure of Sampling Adequacy 0.906

Bartlett's Test of Sphericity

\begin{tabular}{cc} 
Approx. Chi-Square & 1687.184 \\
Df & 276 \\
Sig. & .000 \\
\hline
\end{tabular}

The Skewness, multi-collinearity, measure of sampling adequacy (MSA) was tested and by principal component analysis (PCA) as well as varimax rotation are derived.

\section{The results}

In this section, the results of the factor analysis are presented. Due to the variable weights for each table, all the variables are sorted by highest to lowest weight.

\subsection{Knowledge management processes}

The first variable of the factor analysis is knowledge management processes, which influences on KM. This factor includes five variables including Knowledge acquisition, Knowledge creation, Knowledge store, Team working, KM financial support. Cronbach alpha has been calculated as 79.4\% and Table 3 shows details of our findings.

Table 3

The summary of factors associated with knowledge management process

\begin{tabular}{lcccc}
\hline \multirow{2}{*}{ variables } & Sorted Factor Weight & \multicolumn{3}{c}{ Rotation Sums of Squared Loadings } \\
\cline { 3 - 5 } & & Total & \% of Variance & Cumulative \% \\
\hline KM financial support & 0.721 & & & \\
Knowledge store & 0.709 & 3.441 & 18.112 & \\
Team working & 0.663 & & & \\
Knowledge acquisition & 0.633 & & & \\
Knowledge creation & 0.627 & &
\end{tabular}

\subsection{Innovation}

The second variable of the factor analysis is innovation. This factor includes four variables including competitive advantage, turnover, product introduction, employee performance. Cronbach alpha has been calculated as $70.3 \%$ and Table 4 shows details of our findings.

\section{Table 4}

The summary of factors associated with innovation

\begin{tabular}{lcccc} 
& \multirow{2}{*}{ variables } & Sorted Factor Weight & \multicolumn{2}{c}{ Rotation Sums of Squared Loadings } \\
\cline { 5 - 5 } & .726 & & \%otal & Cumulative \% $\%$ \\
\hline Competitive advantage & .628 & \multirow{2}{*}{2.383} & 12.544 & 30.656 \\
Turnover & .577 & & & \\
Employee performance & .366 & & \\
Product introduction & & & \\
\hline
\end{tabular}




\subsection{Human resource management}

The third variable of the factor analysis is human resource management, which influences on knowledge management. This factor includes four variables including employees tend to learn, organizational structure, employees skills and experience, continuous improvement. Cronbach alpha has been calculated as $65 \%$ and Table 5 shows details of our findings.

\section{Table 5}

The summary of factors associated with HRM

\begin{tabular}{|c|c|c|c|c|}
\hline \multirow{2}{*}{ variables } & \multirow{2}{*}{$\begin{array}{l}\text { Factor } \\
\text { Weight }\end{array}$} & \multicolumn{3}{|c|}{ Rotation Sums of Squared Loadings } \\
\hline & & Total & $\%$ of Variance & Cumulative \% \\
\hline Employees tend to learn & .803 & \multirow{4}{*}{2.056} & \multirow{4}{*}{10.821} & \multirow{4}{*}{41.477} \\
\hline Organizational Structure & .752 & & & \\
\hline Employees skills and experience & .642 & & & \\
\hline Continuous improvement & .352 & & & \\
\hline
\end{tabular}

\subsection{Top management support}

The fourth variable of the factor analysis is top management support, which influences on knowledge management. This factor includes three variables including management support of training and knowledge development, management support of IT development, using knowledge of the insurance industry. Cronbach alpha has been calculated as $65.8 \%$ and Table 6 shows details of our findings.

\section{Table 6}

The summary of factors associated with top management support

\begin{tabular}{|c|c|c|c|c|}
\hline \multirow{2}{*}{ Variables } & \multirow{2}{*}{ Factor Weight } & \multicolumn{3}{|c|}{ Rotation Sums of Squared Loadings } \\
\hline & & Total & $\%$ of Variance & Cumulative \% \\
\hline Management support of IT development & 0.756 & \multirow{3}{*}{1.716} & \multirow{3}{*}{9.032} & \multirow{3}{*}{50.509} \\
\hline Using knowledge of the insurance industry & 0.693 & & & \\
\hline $\begin{array}{l}\text { Management support of training and knowledge } \\
\text { development }\end{array}$ & 0.444 & & & \\
\hline
\end{tabular}

\subsection{Information technology}

The fifth variable of the factor analysis is information technology, which influences on knowledge management. This factor includes three variables including information security, automation, and IT infrastructure. Cronbach alpha has been calculated as $64.1 \%$ and Table 6 shows details of our findings.

\section{Table 7}

The summary of factors associated with information technology

\begin{tabular}{lllcc}
\hline \multirow{2}{*}{ Variables } & Sorted Factor & \multicolumn{3}{c}{ Rotation Sums of Squared Loadings } \\
\cline { 5 - 5 } & Weight & Total & \% of Variance & Cumulative \% \\
\hline Information Security & 0.848 & & & \\
Automation & 0.664 & 1.661 & 8.740 & 59.249 \\
IT infrastructure & 0.424 & & & \\
\hline
\end{tabular}

At the end of the first order exploratory factor analysis, we entered new factors as a variable in SPSS for beginning the second order exploratory factor analysis. The MSA for new Factors is larger than 0.5 and the KMO for all factors were as follows, 


\section{Table 8}

The summary of KMO and Bartlett's test of Sphericity

Kaiser-Meyer-Olkin Measure of Sampling Adequacy

Bartlett's Test of Sphericity 0.824

In addition, the Correlation Matrix determinant is greater than zero. To investigate the items loaded on the identified factors, the factor loadings before and after rotation are used to summarize the results of which are shown in Table 9 as follows,

\section{Table 9}

Total Variance Explained

\begin{tabular}{|c|c|c|c|c|c|c|c|c|c|}
\hline \multirow[b]{2}{*}{ Component } & \multicolumn{3}{|c|}{ Initial Eigenvalues } & \multicolumn{3}{|c|}{ Extraction Sums of Squared Loadings } & \multicolumn{3}{|c|}{ Rotation Sums of Squared Loadings } \\
\hline & Total & $\begin{array}{c}\% \text { of } \\
\text { Variance }\end{array}$ & $\begin{array}{c}\text { Cumulative } \\
\% \\
\end{array}$ & Total & $\begin{array}{c}\% \text { of } \\
\text { Variance }\end{array}$ & $\begin{array}{c}\text { Cumulative } \\
\% \\
\end{array}$ & Total & $\begin{array}{c}\% \text { of } \\
\text { Variance }\end{array}$ & $\begin{array}{c}\text { Cumulative } \\
\% \\
\end{array}$ \\
\hline 1 & 2.725 & 54.503 & 54.503 & 2.725 & 54.503 & 54.503 & 2.219 & 44.376 & 44.376 \\
\hline 2 & .705 & 14.109 & 68.612 & .705 & 14.109 & 68.612 & 1.212 & 24.236 & 68.612 \\
\hline 3 & .613 & 12.254 & 80.866 & & & & & & \\
\hline 4 & .515 & 10.302 & 91.167 & & & & & & \\
\hline 5 & .442 & 8.833 & 100.000 & & & & & & \\
\hline
\end{tabular}

\section{Table 10}

\section{Component Matrix ${ }^{\mathrm{a}}$}

\begin{tabular}{lcc}
\hline & Component & 2 \\
\hline HR & 1 & \\
Management's & .793 & -.360 \\
Process & .769 & \\
IT & .765 & .726 \\
Innovation & .703 & .653 \\
\hline
\end{tabular}

\section{Table 11}

Rotated Component Matrix ${ }^{\mathrm{a}}$

\begin{tabular}{|c|c|c|}
\hline & \multicolumn{2}{|c|}{ Component } \\
\hline & 1 & 2 \\
\hline process & .842 & \\
\hline HR & .740 & \\
\hline IT & .705 & \\
\hline Managements & 651 & .409 \\
\hline Innovation & & .955 \\
\hline
\end{tabular}

\section{Conclusion}

Formulating strategies of the company is mostly based on the competitive advantages of each company and its capabilities to use the opportunities in the most useful way. Competitive core of knowledge based companies is their experience and knowledge together with innovation in idea generation for offering the best solutions for the customers. In service industry, it is very important that we recognize our faults and try to avoid facing such problems while improving past successful 
experiences is very useful for further services. In this study, we have tried to define the main knowledge management and innovation variables, which help the company to formulate its strategies more efficient. Fig. 2 summarizes the results of our findings.

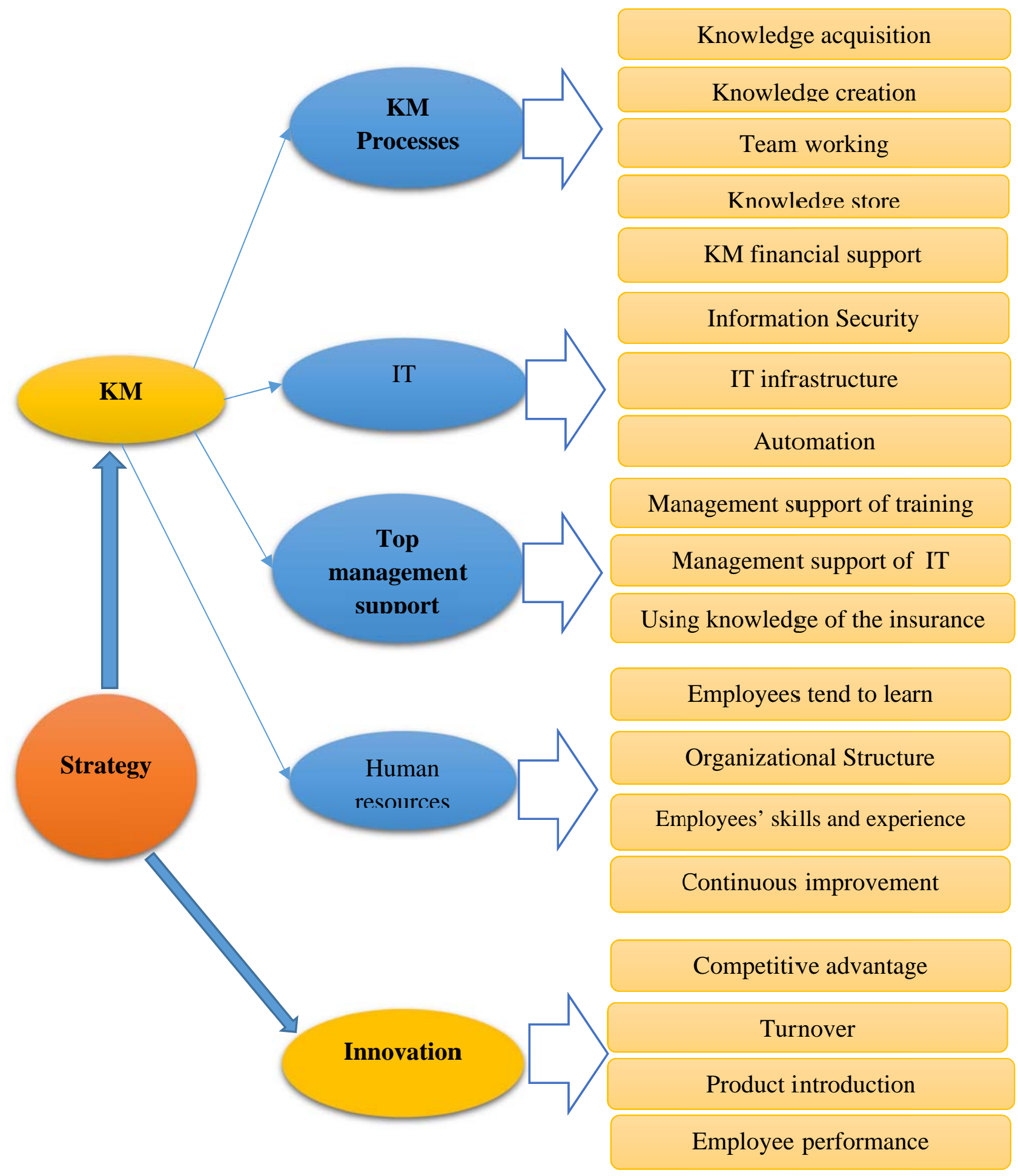

\section{References}

Fig. 2. The final model

Akhavan, P., Jafari, M., \& Fathian, M. (2006). Critical success factors of knowledge management systems: a multi-case analysis. European Business Review, 18(2), 97-113. 
Alavi, M., \& Leidner, D. E. (2001). Review: Knowledge management and knowledge management systems: Conceptual foundations and research issues. MIS Quarterly, 107-136.

Asl, M. B., Khalilzadeh, A., Youshanlouei, H. R., \& Mood, M. M. (2012). Identifying and ranking the effective factors on selecting Enterprise Resource Planning (ERP) system using the combined Delphi and Shannon Entropy approach. Procedia-Social and Behavioral Sciences, 41, 513-520.

Bairi, J., Manohar, B. M., \& Kundu, G. K. (2013). Knowledge acquisition by outsourced service providers from aging workforce of oil and gas industry: A study. VINE, 43(1), 39-56.

Benbya, H., Passiante, G., \& Aissa Belbaly, N. (2004). Corporate portal: a tool for knowledge management synchronization. International Journal of Information Management, 24(3), 201-220.

Chen, C. J., Huang, J. W., \& Hsiao, Y. C. (2010). Knowledge management and innovativeness: The role of organizational climate and structure. International Journal of Manpower, 31(8), 848-870.

Girard, J. P., \& McIntyre, S. (2010). Knowledge management modeling in public sector organizations: a case study. International Journal of Public Sector Management, 23(1), 71-77.

Hung, R. Y. Y., Lien, B. Y. H., Yang, B., Wu, C. M., \& Kuo, Y. M. (2011). Impact of TQM and organizational learning on innovation performance in the high-tech industry. International Business Review, 20(2), 213-225.

Huang, L. S., \& Lai, C. P. (2012). An investigation on critical success factors for knowledge management using structural equation modeling. Procedia-Social and Behavioral Sciences, 40, 24-30.

Jha, S. (2011). Human resource management and knowledge management: Revisiting challenges of integration. International Journal of Management \& Business studies, 1(2), 56-60.

Jiménez-Jiménez, D., \& Sanz-Valle, R. (2011). Innovation, organizational learning, and performance. Journal of Business Research, 64(4), 408-417.

Lee, H., \& Choi, B. (2003). Knowledge management enablers, processes, and organizational performance: an integrative view and empirical examination.Journal of management information systems, 20(1), 179-228.

Lin, H. F. (2007). Knowledge sharing and firm innovation capability: an empirical study. International Journal of Manpower, 28(3/4), 315-332.

Liao, S. H., \& Wu, C. C. (2010). System perspective of knowledge management, organizational learning, and organizational innovation. Expert Systems with Applications, 37(2), 1096-1103.

López-Nicolás, C., \& Meroño-Cerdán, Á. L. (2011). Strategic knowledge management, innovation and performance. International Journal of Information Management, 31(6), 502-509.

Sedighi, M., \& Zand, F. (2012, November). Knowledge management: Review of the Critical Success Factors and development of a conceptual classification model. In ICT and Knowledge Engineering (ICT \& Knowledge Engineering), 2012 10th International Conference on (pp. 1-9). IEEE.

Škerlavaj, M., Song, J. H., \& Lee, Y. (2010). Organizational learning culture, innovative culture and innovations in South Korean firms. Expert systems with applications, 37(9), 6390-6403.

Xiang-yang, L. (2007, August). A Systems Thinking Model for Innovation Management: The Knowledge Management Perspective. In Management Science and Engineering, 2007. ICMSE 2007. International Conference on (pp. 1499-1504). IEEE.

Xu, J., Houssin, R., Caillaud, E., \& Gardoni, M. (2010). Macro process of knowledge management for continuous innovation. Journal of Knowledge Management, 14(4), 573-591. 